\title{
Development of approach to modelling and optimization of non-stationary catalytic processes in oil refining and petrochemistry
}

\author{
Irena O. Dolganova*, Igor M. Dolganov, Elena N. Ivashkina, Emilia D. Ivanchina, \\ Rostislav V. Romanovskiy
}

Tomsk Polytechnic University, 30, Lenin Avenue, Tomsk, 634050, Russia

"Corresponding author: e-mail: dolganovaio@sibmail.com

\begin{abstract}
An approach to modelling of non-stationary catalytic processes of oil refining and petrochemistry is proposed. The computer modelling systems under development take into account the physical and chemical reaction laws, raw materials composition, and catalyst nature. This allows using the software for the optimization of process conditions and equipment design. The models created can be applied for solving complex problems of chemical reactors design; calculation of different variants of industrial plants reconstruction; refining and petrochemicals catalysts selection and testing; catalyst service life prolongation; determination of optimum water supply into the alkanes dehydrogenation reactor; optimization of products separation in the benzene alkylation process.
\end{abstract}

Keywords: oil refining, mathematical model, non-stationary, technological mode, forecasting.

\section{INTRODUCTION}

The majority of industrial reactors and technological schemes for thermal and catalytic processes of petroleum and gas refining were designed and built in the middle of the $20^{\text {th }}$ century. They are still operated at some Russian refineries. The construction of these industrial plants is based on a classical approach: laboratory apparatus pilot testing - pilot reactor - industrial reactor ${ }^{1}$. As a result, oil refining and petrochemical industry obtained chemical apparatus created with a large degree of safety regardless the catalysts operational properties.

Mathematical modeling allows choosing the optimal technological solutions that get advantage of the catalysts resources to a maximum extent.

This article describes an innovative approach to mathematical modeling and optimization of the non-stationary catalytic processes in oil refining and petrochemistry.

The first mathematical models of reactor processes were designed according to the "black box" type, and did not take the detailed mechanism of the subsequent reactions and catalysts adsorption properties into account.

One of the first attempts was that of Smith ${ }^{2}$ who tried to describe the detailed mechanism and kinetics of hydrocarbons transformation on Pt-catalysts in 1959. After that, researchers ${ }^{3}$ moved towards the simplified reaction network reducing the dimensionality of mathematical model by distributing the parameters depending on the number of carbon atoms in a hydrocarbon molecule. Isomers were combined into the groups of pseudo components ${ }^{4}$.

In the 80 -s of the $20^{\text {th }}$ century the studies on the mathematical modeling of the multicomponent catalytic processing of petroleum feedstock were developed ${ }^{2}$. As a result of the studies on the kinetics and mechanism of the reactions proceeding on Pt-catalysts in the gasoline reforming process, as well as a detailed thermodynamic analysis, the formal mechanism was proposed for the transformation of hydrocarbons $\mathrm{C}_{5}-\mathrm{C}_{12}$ from different homology groups in the temperature range of $700-800$ $\mathrm{K}$. This scheme served as the basis for time-dependent kinetic model of the process. The advantage of this scheme is the fact that it takes into account the conversion of mono- and di-substituted naphthenes. The proposed reaction network is sensitive to changes in raw material composition containing more than 180 components.

The developed kinetic model became the basis for the computer modeling system of gasoline catalytic reforming. This software was one of the first to be implemented in a number of Russian refineries.

With the use of this simulator, calculations were carried out and recommendations were issued as to the reforming units reconstruction: in particular, the design modification of reactors internal devices with radial supply of raw materials in a stationary granular catalyst bed $^{5}$. Implementation of scientific results ensured the increase of the product yield by $2.5-3 \%$ with octane number of 93 points.

Moreover, the developed intelligent system is successfully applied for reforming the catalysts selection and testing, as well as the estimation of their life cycle in terms of technological conditions and raw material composition.

This scientific approach to modeling of the non-stationary catalytic processes was used in the development of computer simulation for the complex of linear alkyl benzene $(\mathrm{LAB})$ production, comprising the sequential stages of $\mathrm{C}_{9}-\mathrm{C}_{14}$ alkenes dehydrogenation, dienes hydrogenation and benzene alkylation with alkenes.

\section{EXPERIMENTAL}

The essence of the approach to mathematical modeling of petroleum refining processes is as follows:

1. Estimation of the thermodynamic probability of chemical reactions under certain technological conditions.

This stage of modeling requires the application of quantum-chemical methods for the calculation of reactions thermodynamic parameters. In our case Gaussian (PM3 procedure) and HyperChem 8 (method "ab initio", basis $3-21 \mathrm{G}$ ) software products were used. In addition, the electronic structures of molecules and the main thermodynamic parameters (enthalpy and entropy changes, Gibbs energies of each reaction) were calculated ${ }^{6}$. 
2. Development of the detailed reaction network for hydrocarbons transformations in the process of interest and its formalization.

3. Identification of key process efficiency indicators.

4. Evaluation of hydrodynamic regime in the reactor.

5. Development of the process mathematical description and its software implementation.

To improve the accuracy of the mathematical description, it is recommended to consider the process non-stationarity due to the catalyst deactivation by carbon compounds.

6. Identification of the kinetic parameters in the mathematical model (solving the inverse kinetic problem).

The implementation of this simulation stage requires the use of theoretical or experimental methods. This paper describes the application of transition state theory to the development of algorithm for kinetic parameters identification.

7. Verification of the mathematical model validity attained by comparison of the calculated and experimental data.

The mathematical model designed thereby takes the physical-and-chemical laws of the reactions into account, as well as the composition of the reaction mixture, and the catalyst nature. Several areas of the chemical process optimization with the use of the computer modeling system can be distinguished:

1. Monitoring the industrial unit operation.

2. Selecting the optimal technological conditions for conducting specific processes.

3. Efficiency analysis and comparison of different industrial unit reconstruction options.

Formalization of higher alkanes dehydrogenation process mechanism during its simulation

The transformation of 7 groups of hydrocarbons in 8 types of chemical reactions was examined ${ }^{7}$ to propose the formalized scheme of hydrocarbons conversion on Pt-catalysts surface, which allowed solving important technological problems associated with the selection of industrial unit reconstruction options during the transition to a double-reactor scheme of operation. Reaction network of alkane hydrocarbons dehydrogenation was formed not only according to their reactivity, but also with regard to their contribution to the final product overall quality factor - its biochemical degradability. Biodegradability of alkyl sulphonates obtained from normal alkanes is $98 \%$, while that of alkenesulphonates is $90-95 \%$, and that of alkylsulphonates $\left(C_{10-18}\right)$ is $97.9 \%$.

This formalized reaction network became the basis for the development of the kinetic model of the dehydrogenation process.

The development of the dehydrogenation process mathematical model took into consideration the factors of its unsteadiness caused by catalyst deactivation with coke-forming products. The method for calculating the optimal dynamics of water supply into the dehydrogenation reactor was developed and implemented.

To this end, further studies on the mechanism and kinetics of dehydration process were carried out, which ensured a more precise definition of the reaction network. This stage of simulation required the application of quantum-chemical calculation methods for obtaining the thermodynamic parameters of reactions involving hydrocarbons $\mathrm{C}_{9}-\mathrm{C}_{14}$.

The result showed that 11 groups of pseudo components were involved in 22 types of chemical reactions (Fig. 1).

\section{Reducing the dimension of the alkylation process ma- thematical description}

Alkylation of benzene with higher alkenes is the final stage of LAB manufacturing.

It is known from the published sources that the conditions of alkylation process determine the yield and the composition of the obtained alkylbenzenes.

The prerequisite for this stage of simulation was the fact that it is the structure of LAB that affects both the biological degradability of synthetic detergents and their solubility and washing performance. The detergents biodegradability is primarily affected by the structure of the side hydrocarbon chain in the LAB molecule: unlike the previously widely used alkylbenzenes with branched hydrocarbon chain, "linear" alkylbenzenes and corresponding synthetic detergents (SD) are almost completely decomposed by bacteria in natural conditions ${ }^{\mathbf{8}}$. Another factor determining SD biodegradability is the fraction

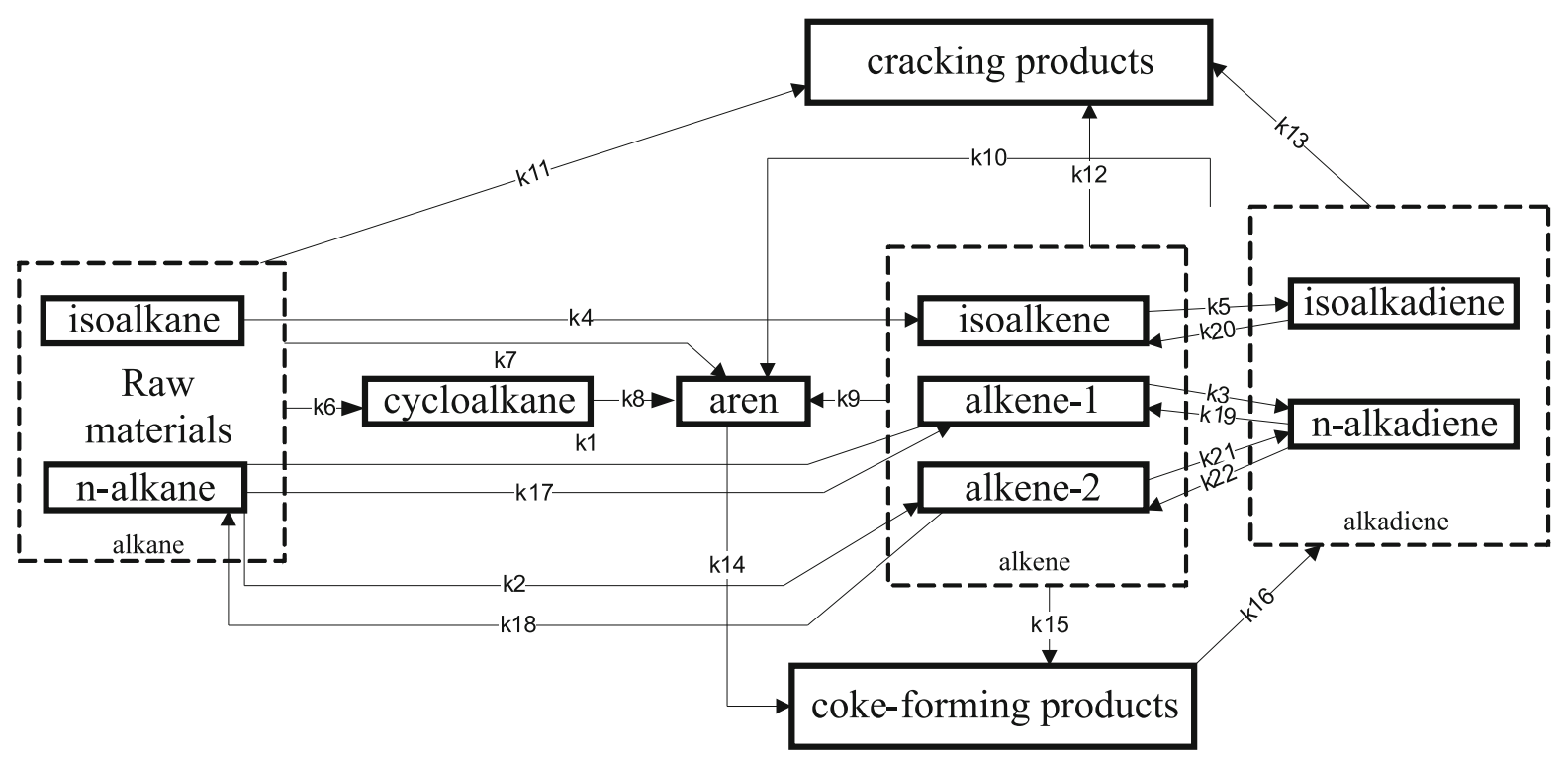

Figure 1. Formalized reaction network of the dehydrogenation process 
of 2-phenilalkanes among other isomers obtained. The high content of 2-phenilalkanes in LAB also increases the solubility of detergents, which positively affects their cleaning characteristics.

The length of the hydrocarbon radical in $\mathrm{LAB}$ also affects the SD cleaning ability, and fraction $\mathrm{C}_{11}-\mathrm{C}_{12}$ has the best characteristics (according to Yadav et al., 2002).

The complexity of this process modeling is caused by the fact that it is multicomponent: raw material is $\mathrm{C}_{9}-\mathrm{C}_{14}$ fraction of alkenes delivered from dehydrogenation stage. There are numerous variants of reactions with different isomers, as well as diverse combinations of substances, e.g. at the formation of dialkylbenzenes.

Thermodynamic analysis for estimating the probability of reaction occurrence under these conditions also requires certain consolidation of individual substances in groups of substances and combination of reactions into the types.

However, when substances are aggregated into reaction series, the formalized model should retain its sensitivity to variations in raw materials composition, as well as its informativity in terms of target products and the byproducts yield.

For the most complete description of the target product quality it is necessary to consider not only the isomerism of the side chain carbon skeleton, but also the location of the double bond in the reacting alkene, since this affects the biological degradability of SD obtained.

Given the fact that the content of 2-phenilalkanes in $\mathrm{LAB}$ is an important industrial and regulated parameter, it is reasonable to separate the reactions of their formation within the reaction network.

An important characteristic of the target and the byproducts of alkylation process is a bromine number (BN) which is directly related to the mass of unsaturated compounds in the product flow:
$B N=\frac{X_{u n s} \cdot 160}{M_{u n s}}$

The concentration of unsaturated alkyl aromatic compounds influences the product bromine number, and, accordingly, the reaction network should include reactions of unsaturated alkylbenzenes and dialkylbenzenes formation.

The values of thermodynamic properties for the reactions of benzene alkylation with decene are listed in Table 1.

Thermodynamic characteristics were calculated using HyperChem 8 - software for quantum chemical calculations (ab initio method, basis 3-21G), whereas the enthalpies of substances formation were calculated with the PM3 semi-empirical method.

Considering all the above-mentioned points, the resulting reaction network will look like the following (Fig. 2).

Where Alkenes-1,2 - alkenes $\mathrm{C}_{10}-\mathrm{C}_{14}$ of linear structure with the double bond after the first and second carbon atoms; Alkenes int - alkenes $\mathrm{C}_{10}-\mathrm{C}_{14}$ of the linear structure with double bond after the third and forth carbon atoms; BAB - branched alkylbenzenes (alkylbenzenes with side chain of branched structure); DAB - dialkylbenzenes; LAB-2 - 2-phenilalkanes; $\mathrm{LAB}_{\text {int }}$ - 3,4-phenilalkanes; $\mathrm{LAB}_{\text {uns }}$ - alkylbenzenes with unsaturated side chain; $\mathrm{DAB}_{\text {uns }}$ - dialkylbenzenes with unsaturated side chain; Dienes - dienes of linear and branched structure; DPA - diphenylalkanes.

\section{Development of mathematical description}

Based upon the presented reaction network, the kinetic model of alkylation process was developed. Table 2 contains the expressions for the chemical reaction rates for each component that were calculated according to the law of mass action.

Table 1. Thermodynamic characteristics of benzene alkylation with decene reactions $(\mathrm{T}=328 \mathrm{~K})$

\begin{tabular}{|l|c|c|c|}
\hline Reaction & $\Delta G, \mathrm{~kJ} / \mathrm{mole}$ & $\Delta H, \mathrm{~kJ} / \mathrm{mole}$ & Equilibrium constant \\
\hline 1. Benzene+Alkene-1,2=LAB-2 & -42.98 & -96.11 & 1.016 \\
\hline 2. Benzene+Alkene-3,4..=LAB-3,4.. & -22.86 & -74.62 & 1.008 \\
\hline 3. Benzene+i-Alkene=BAB & -6.47 & -80.40 & 1.002 \\
\hline 4. Alkene-3,4..=IsoAlkene & 2.02 & 0.28 & 0.999 \\
\hline 5. Alkene-1,2=Alkene-3,4.. & 9.85 & 3.64 & 0.996 \\
\hline 6. $p$ seudoLAB+pseudoAlkene=DAB & -26.56 & -85.63 & 1.010 \\
\hline 7. Benzene+Diene=LAB & -68.75 & 1.003 \\
\hline 8. uAB $_{\text {uns }}+p s e u d o A l k e n e=D A B_{\text {uns }}$ & -8.50 & -43.53 & 1.0002 \\
\hline 9. Benzene+LAB & -0.53 & \\
\hline
\end{tabular}

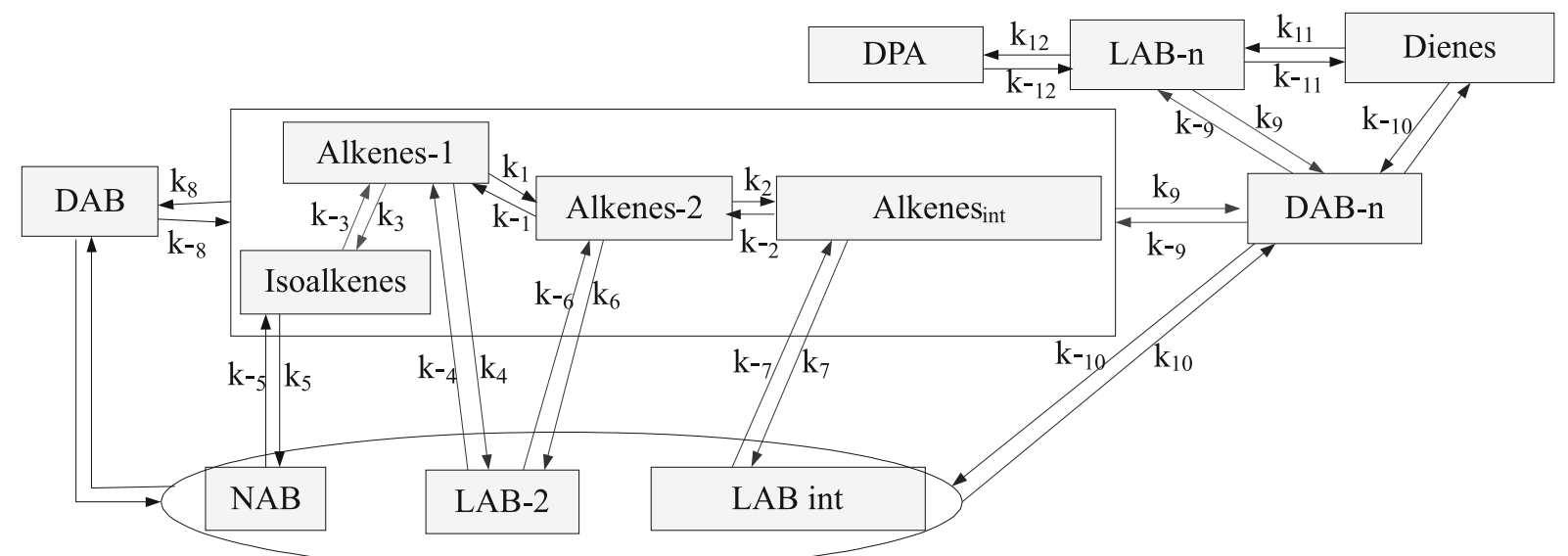

Figure 2. Formalized reaction network of alkylation process 
Table 2. Expressions for rates of reactions in alkylation process

\begin{tabular}{|c|c|c|}
\hline \multirow{2}{*}{ Reaction type } & \multicolumn{2}{|c|}{ Expressions for rates of reactions: } \\
\hline & Direct reaction & Inverse reaction \\
\hline $\begin{array}{l}\text { Isomerization of alkanes according to double } \\
\text { bond position }\end{array}$ & $\begin{array}{l}W_{1}=k_{1} C_{\text {alken-1 }} \\
W_{2}=k_{2} C_{\text {alken-2 }}\end{array}$ & $\begin{array}{l}W_{-1}=k_{-1} C_{\text {alken-2 }} \\
W_{-2}=k_{-2} C_{\text {alken }_{\text {int }}}\end{array}$ \\
\hline $\begin{array}{l}\text { Isomerization of alkenes according to structure of } \\
\text { carbon chain }\end{array}$ & $W_{3}=k_{3} C_{\text {alken-1 }}$ & $W_{-3}=k_{-3} C_{\text {isooalken }}$ \\
\hline LAB formation & $\begin{array}{l}W_{4}=k_{4} C_{\text {benzene }} C_{\text {alken-1 }} \\
W_{6}=k_{6} C_{\text {benzene }} C_{\text {alken-2 }} \\
W_{7}=k_{7} C_{\text {benzene }} C_{\text {alken int }} \\
W_{11}=k_{11} C_{\text {benzene }} C_{\text {diene }}\end{array}$ & $\begin{aligned} W_{-4} & =k_{-4} C_{L A B-2} \\
W_{-6} & =k_{-6} C_{L A B-2} \\
W_{-7} & =k_{-7} C_{L A B_{\text {int }}} \\
W_{-11} & =k_{-11} C_{L A B_{\text {uns }}}\end{aligned}$ \\
\hline BAB formation & $W_{5}=k_{5} C_{\text {benzene }} C_{\text {isoalken }}$ & $W_{-5}=k_{-5} C_{B A B}$ \\
\hline DAB formation & $W_{8}=k_{8} C_{p s e u d o L A B} C_{p s e u d o a l k e n}$ & $W_{-8}=k_{-8} C_{D A B}$ \\
\hline $\mathrm{DAB}_{\text {uns }}$ formation & $\begin{array}{l}W_{9}=k_{9} C_{L A B_{\text {uns }}} C_{\text {pseudoolefin }} \\
W_{10}=k_{10} C_{\text {pseudoLAB }} C_{\text {diolefin }}\end{array}$ & $\begin{aligned} W_{-9} & =k_{-9} C_{D A B_{u n s}} \\
W_{-10} & =k_{-10} C_{D A B_{u n s}}\end{aligned}$ \\
\hline DPA formation & $W_{12}=k_{12} C_{\text {benzene }} C_{D A B_{\text {uns }}}$ & $W_{-12}=k_{-12} C_{D P A}$ \\
\hline
\end{tabular}

According to this kinetic model now looks like the following:

$$
\left\{\begin{array}{l}
\frac{d C_{\text {alken-1 }}}{d t}=-k_{1} C_{\text {alken-1 }}+k_{-1} C_{\text {alken-2 }}-k_{3} C_{\text {alken-1 }}+k_{-3} C_{\text {issalken }}-k_{4} C_{\text {benzene }} C_{\text {alken-1 }}+k_{-4} C_{\mathrm{LAB}} \\
\frac{d C_{\text {alken-2 }}}{d t}=k_{1} C_{\text {alken-1 }}-k_{-1} C_{\text {alken-2 }}-k_{2} C_{\text {alken-1 }}+k_{-2} C_{\text {alken-3,4.7.7 }}-k_{6} C_{\text {benzene }} C_{\text {alken-2 }}+k_{-6} C_{\mathrm{LAB}} \\
\frac{d C_{\mathrm{LAB}-2}}{d t}=k_{4} C_{\text {benzene }} C_{\text {alken-1 }}-k_{-4} C_{\mathrm{LAB}}+k_{6} C_{\text {benzene }} C_{\text {alken-2 }}+k_{-6} C_{\mathrm{LAB}}
\end{array}\right.
$$

The initial conditions: $t=0, C_{i}=C_{0 i}$.

The constants $\mathrm{k}_{1}-\mathrm{k}_{12}$ and $\mathrm{k}_{-1}-\mathrm{k}_{-12}$ are effective since they represent the combination of the constants for all intermediate stages.

In the stationary regime, given the hydrodynamic mode of ideal displacement, the change in the hydrocarbon concentration in terms of the reactor volume (contact time) can be written as follows:

$\frac{d C_{i}}{d \tau}=W_{i}$

For the evaluation of the hydrodynamic regime in the reactor the Peclet criterion calculation can be used ${ }^{8}$. This criterion expresses the ratio of convective and turbulent transport of the matter and can be calculated as follows: $P e=U^{*} l / D$

For the lengthy catalyst bed and the low intensity of mixing, Peclet criterion value is large and it corresponds to the plug-flow reactor model. The assumption on the ideal displacement regime in the alkylation reactor was confirmed by the calculation of Peclet criterion $(403.7>200)^{9}$.

The characteristics of benzene alkylation reactor are adiabatic as there is no heat removal from the reactor. Thus, the heat balance equation in a steady state can be written as follows:

$\rho C_{p} \frac{d T}{d \tau}= \pm \sum_{j=1}^{N}\left(-\Delta H_{j}\right) W_{j}$
Mathematical models of alkanes dehydrogenation and dienes hydrogenation processes were developed similarly.

The active window of the combined computer modeling system simulating three production stages is shown in Fig.3.

The presented above computer modeling system allows the material and heat balances calculation and redetermination; the yield of the target and by-products determination; LAB quality indicators such as bromine index, content of 2-phenylalkanes and linear isomers in the product flow evaluation, the optimal water supply in the dehydrogenation reactor etc.

\section{Algorithm of kinetic parameters identification using the transition state theory}

Transition state theory was developed in the 1930-s by H. Eyring, M. Evans and M. Polanyi and is also known as the theory of the absolute rates of chemical reactions ${ }^{10}$. According to this theory, the rate of elementary chemical reaction can be calculated using the energy characteristics of the transition state:

$k=\chi \frac{k T}{h} e^{\frac{\Delta S^{\#}}{R}} e^{\frac{-\Delta H^{\#}}{R T}} e^{\frac{-E a}{R T}}=\chi \frac{k T}{h} e^{\frac{-\Delta G^{\#}}{R T}} e^{\frac{-E a}{R T}}$

In the case of benzene alkylation with alkenes, the limiting stage of the mechanism is the sigma-complex formation ${ }^{11}$. Thus, thermodynamic characteristics of the transition state formation reaction in the first ap- 


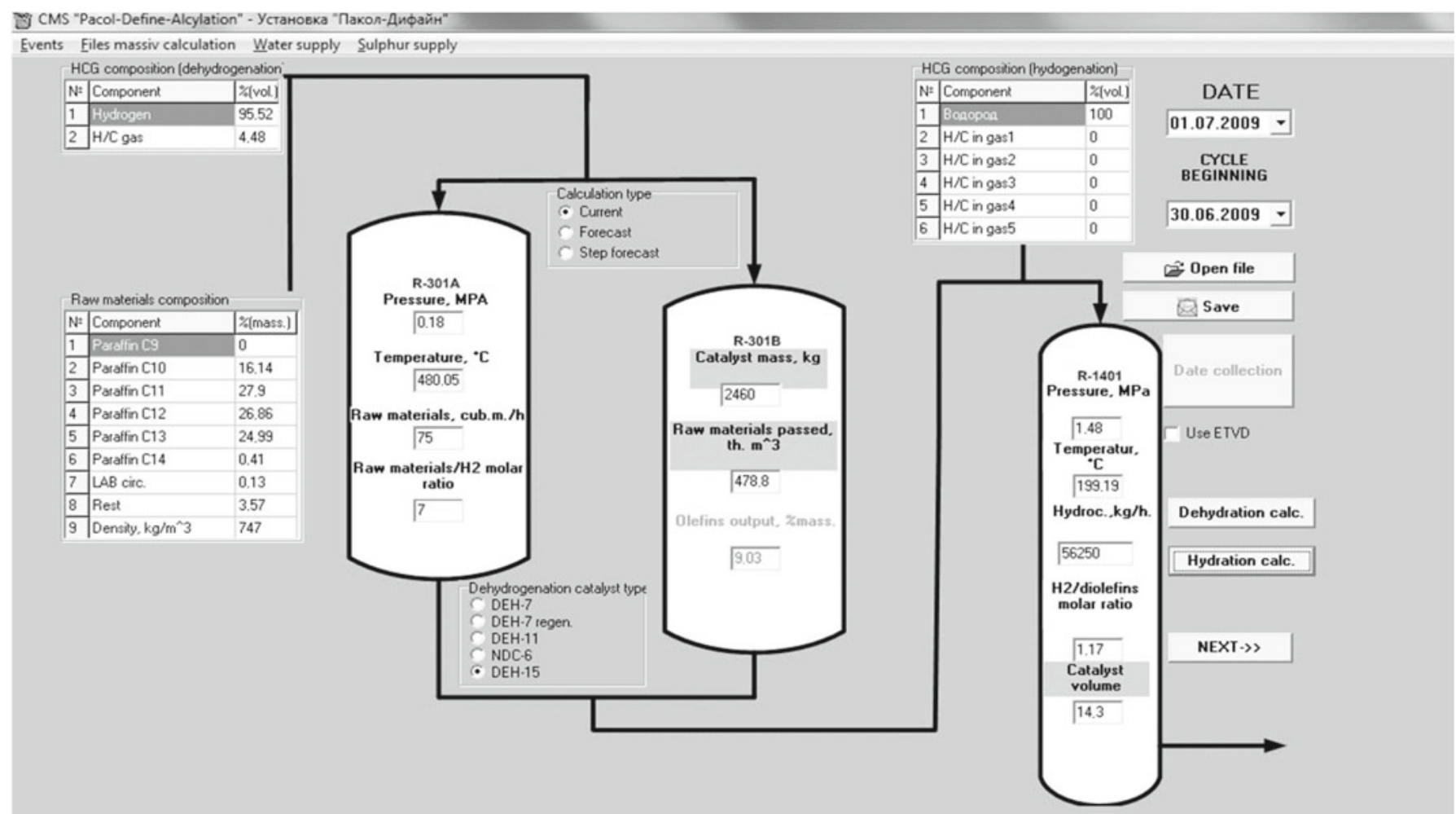

Figure 3. Active window of the combined computer modeling system for LAB production complex

proximation can be used for the calculation of reactions rate constants.

The thermodynamic characteristics of transition states were calculated using HyperChem 8 (ab initio method, basis 3-21G), and are listed in Table 3.

\section{Model validity verification}

The results of comparing the calculated and experimental values of the main output parameters are shown in Fig. 4-5.

The period of verification was from March, 2007 to December, 2010.

It follows that, built with the use of kinetic parameters evaluated values, the mathematical model of the alkylation reactor adequately describes the increase and decrease in the yield of the target and the by-products, as well as the temperature changes in the output flow at the variations of the process conditions and/or raw materials composition.

The mathematical model of alkanes dehydrogenation process also provides a high precision of the experimental and calculated data. Thus, the developed software is applicable to the monitoring and optimization of the appropriate oil refinery processes.

Calculation of the optimal water supply into dehydrogenation reactor

Software implemented mathematical model of dehydration process was used in the calculation of one of the industrial unit reconstruction options which implies a transition to parallel operation of reactors ${ }^{\mathbf{1 0}}$.

It was shown that at the feed flow rate of $37.5 \mathrm{~m}^{3} / \mathrm{h}$ the duration of the catalyst working cycle increases by 1.6-1.7 times in comparison with that of $75 \mathrm{~m}^{3} / \mathrm{h}$ at $\mathrm{H}_{2}$ :raw materials molar ratio of $7: 1$. To reduce the concentration of the by-products it is recommended to increase the molar ratio up to $8: 1$. This allows increasing the catalyst working cycle by up to 2.2 times at the LAB output of 180 tons per day.

Calculation of the optimal water supply into dehydrogenation reactor

Calculated with the developed model of dehydrogenation process, the optimal dynamics of water supply into

Table 3. Thermodynamic characteristics of transition states formation and estimated values of kinetic parameters of direct reactions in alkylation process $(\mathrm{T}=323 \mathrm{~K})$

\begin{tabular}{|c|c|c|c|c|}
\hline Reaction & $\Delta H^{\neq}, \mathrm{kJ} / \mathrm{mole}$ & $\Delta S^{\neq}, \mathrm{kJ} / \mathrm{mole}$ & $E_{a}, \mathrm{~kJ} / \mathrm{mole}$ & Reaction rate constant \\
\hline Benzene+Alkene-1,2=LAB-2 & 42.9 & -137.3 & 87.9 & $6.6 \cdot 10^{-2}$ \\
\hline Benzene+Alkene-3,4..=LAB-3,4.. & 66.9 & -58.0 & 85.9 & $13.9 \cdot 10^{-2}$ \\
\hline Benzene+lsoAlkene=BAB & 50.9 & -107.4 & 86.1 & $13.0 \cdot 10^{-2}$ \\
\hline Alkene-3,4..=i-Alkene & 81.1 & -10.1 & 81.1 & $8.1 \cdot 10^{-1}$ \\
\hline Alkene-1,2=Alkene-3,4.. & 77.4 & -11.8 & 83.6 & $3.31 \cdot 10^{-1}$ \\
\hline pseudoLAB + pseudoAlkene=DAB & 85.2 & -33.9 & 96.3 & $3.0 \cdot 10^{-3}$ \\
\hline Benzene+Diene $=\mathrm{LAB}_{\text {uns }}$ & 73.7 & -31.9 & 84.1 & $2.7 \cdot 10^{-1}$ \\
\hline $\mathrm{LAB}_{\text {uns }}+p$ se udoAlkene $=\mathrm{DAB}_{\text {uns }}$ & 65.4 & -48.4 & 81.3 & $7.5 \cdot 10^{-1}$ \\
\hline Benzene $+\mathrm{LAB}_{\text {uns }}=\mathrm{DPA}$ & 71.4 & -34.9 & 82.9 & $4.3 \cdot 10^{-1}$ \\
\hline
\end{tabular}




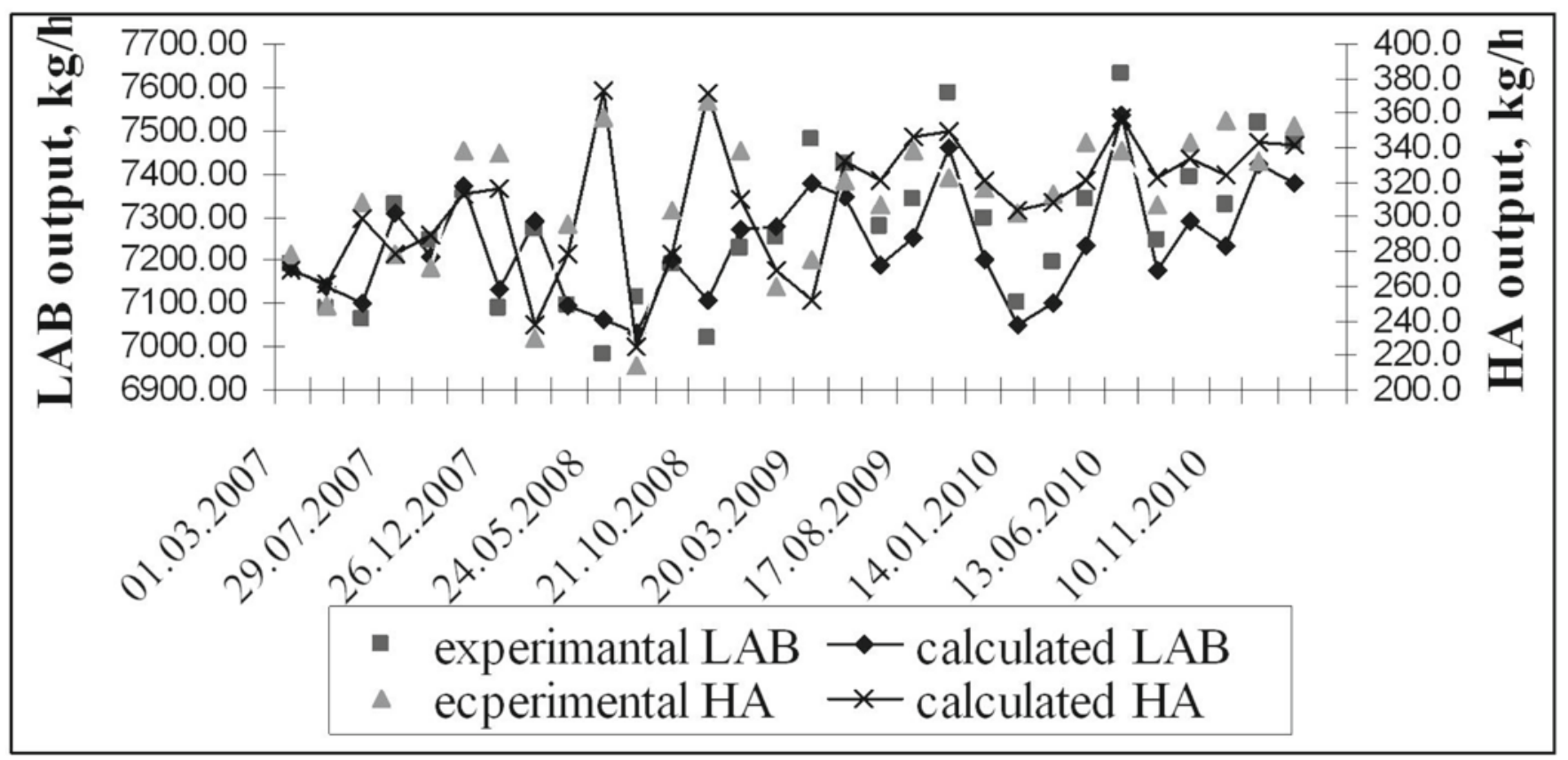

Figure 4. Calculated and experimental yields of the target- and by-product

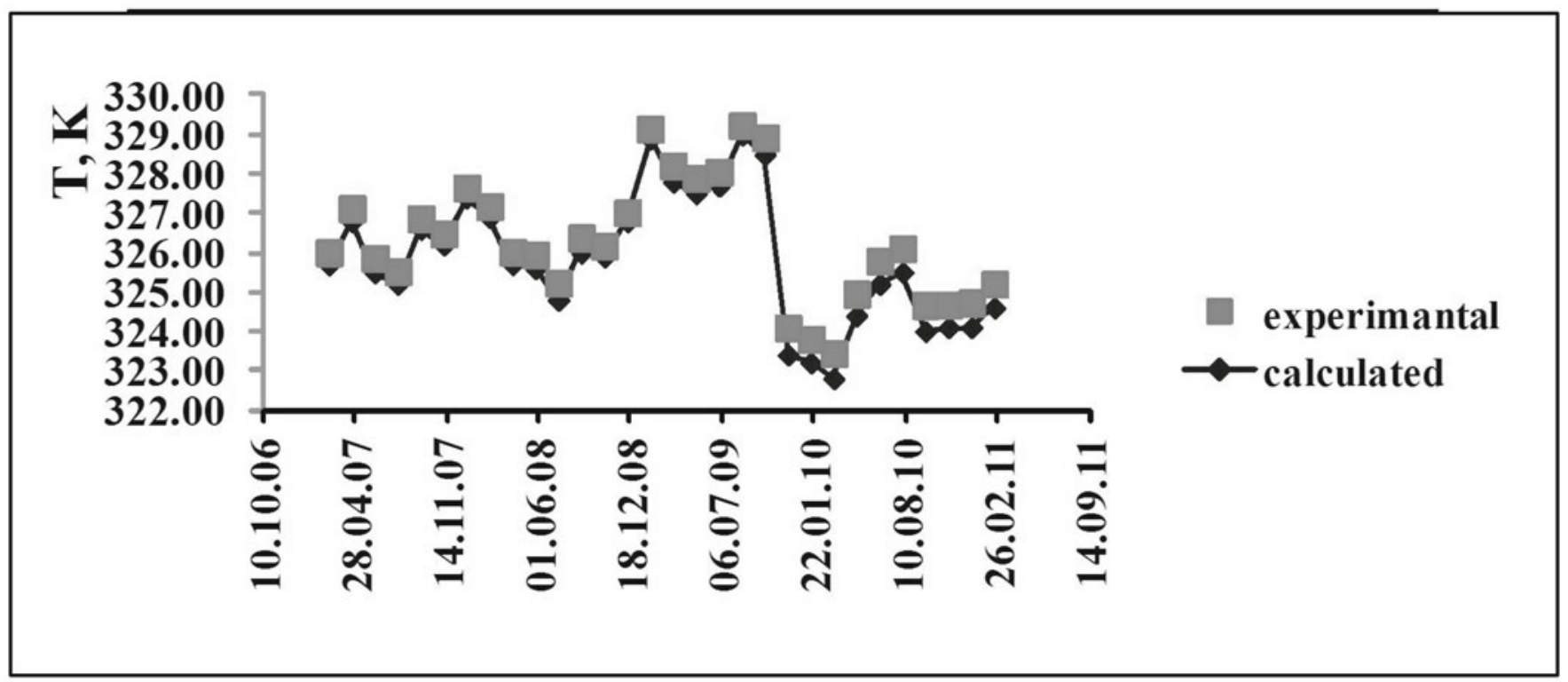

Figure 5. Calculated and experimental values of temperature at the reactor outlet

the reactor allows increasing the resource efficiency of higher hydrocarbons $\mathrm{C}_{9}-\mathrm{C}_{14}$ dehydrogenation technology by reducing the deactivation process and, accordingly, extending the catalyst life cycle.

For the current working cycle the optimal dynamics of water supply from $4 \mathrm{l} / \mathrm{h}$ at the initial temperature of 740 $\mathrm{K}$ to $9 \mathrm{l} /$ hat output temperature of $760 \mathrm{~K}$ will ensure the increase of the cycle duration up to 390 days, compared to a cycle with constant water supply into the reactor under which the cycle duration is 320 days.

Selecting the optimal unreacted raw materials recycling ratio

The use of the combined computer modeling system allowed examining a number of options for establishing the unreacted alkanes recycling after the dehydrogenation reactor (Fig. 6).

From the dependences shown it is obvious that the recycling ratio of 0.3 is the most preferable, since it ensures the growth of alkenes yield by $55.2 \mathrm{~kg}$ (approximately by $44 \%$ ), with the growth of dienes yield being $1.8 \mathrm{~kg}$ per ton of fresh raw material (approximately by $72 \%$ ).

Optimization of alkylation and HF-catalyst regeneration processes with the use of the mathematical model

Using the alkylation process mathematical model, the options with different technological regimes were calculated. From the set of calculation options, the regime satisfying the following optimality criteria was chosen:

Maximal yield of LAB, kg/hour;

Minimal yield of heavy alkylate (HA), kg/hour;

Minimal molar content of HA in the HA/HF mixture;

Maximal molar content of unsaturated hydrocarbons in the $\mathrm{HA} / \mathrm{HF}$ mixture;

Minimal bromine index of LAB;

Minimal bromine number of DAB.

The set of process parameters ensuring the efficient operation of alkylation reactor and acid regeneration column is: temperature $-323 \mathrm{~K}$, benzene flow rate -22 $\mathrm{t} / \mathrm{h}, \mathrm{HF}$ flow rate $-180 \mathrm{t} / \mathrm{h}$. 


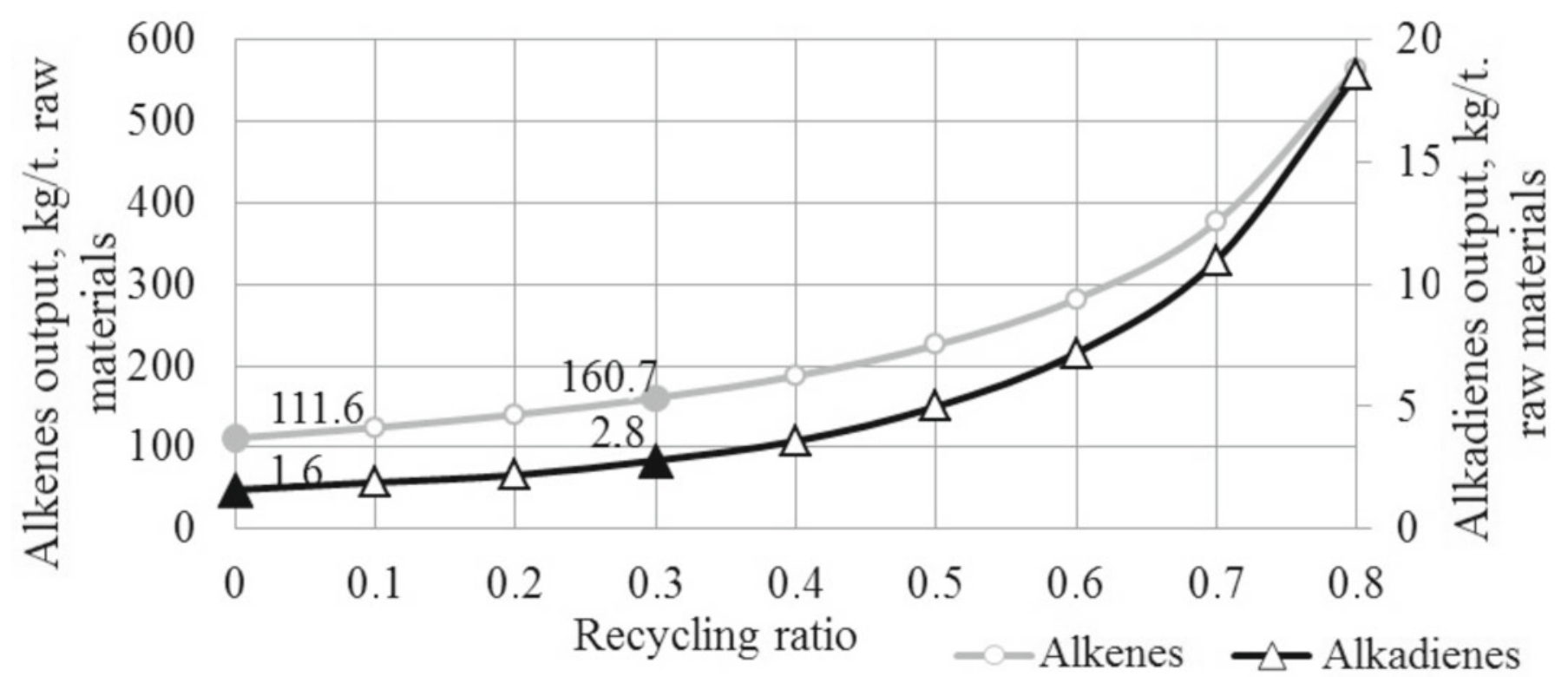

Figure 6. Dependence of alkenes and dienes output on the recycling ratio

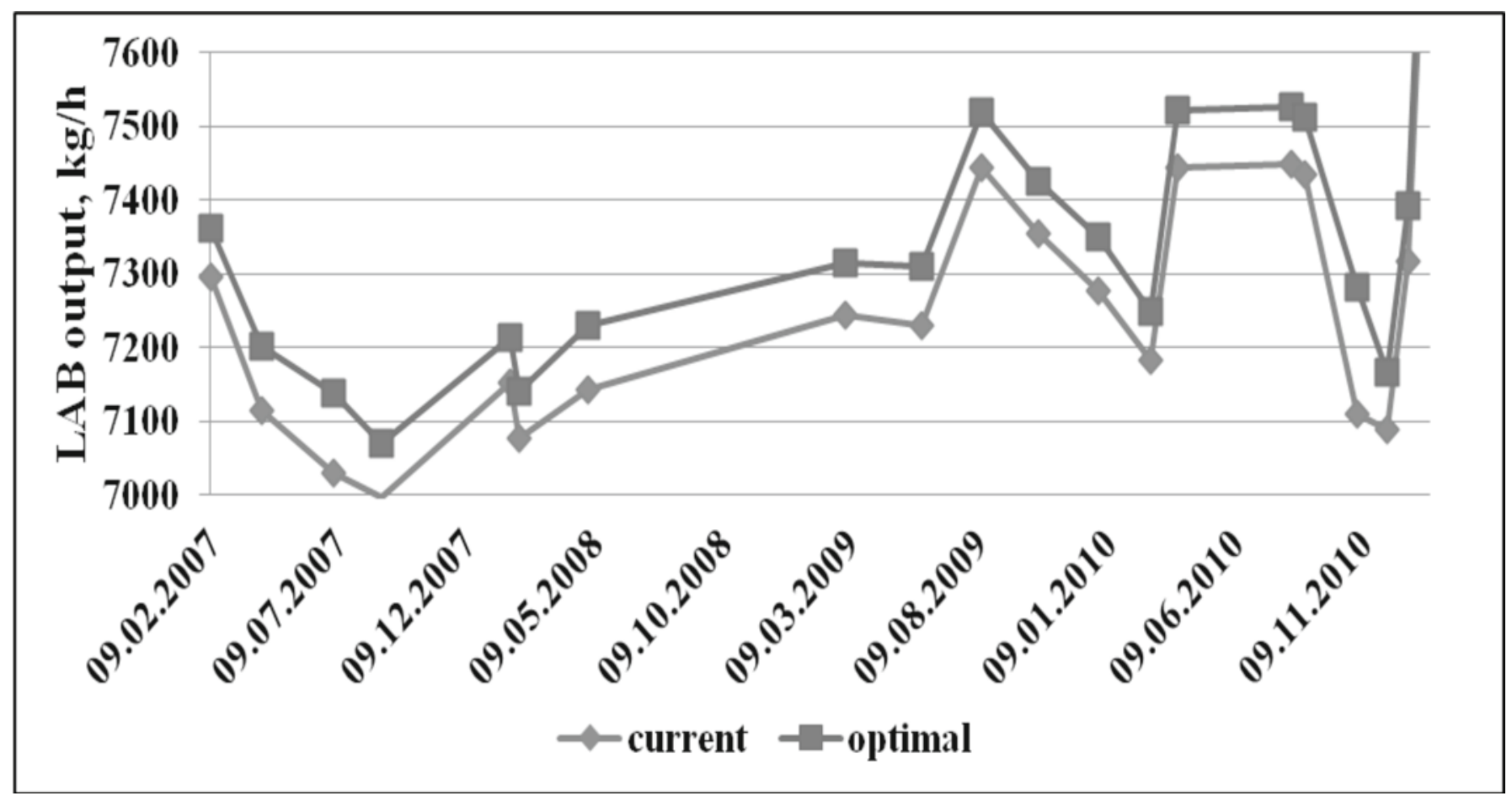

Figure 7. LAB yield under current and optimal technological conditions

Fig. 7, 8 show the results of calculation on the model with the optimal parameters and the comparison of the optimal and the current results.

According to the results, maintaining the optimal technological regime allows having the average $\mathrm{LAB}$ yield growth of $81 \mathrm{~kg} /$ hour and HA yield decline of $65 \mathrm{~kg} /$ hour.

\section{CONCLUSIONS}

Mathematical models for a number of crude oil refining industrial processes were developed on the basis of the proposed approach. Among them are the processes of benzene catalytic reforming, higher alkanes dehydrogenation, benzene alkylation with alkenes, and others. These models were developed considering the following features:

1. Combination of multi-component raw mixture elements into the groups of pseudo components according to their reactivity;
2. Development of the formalized reaction network. Establishing the relation between the reactivity of hydrocarbons from the same homologous group and their detonation resistance (for benzene catalytic reforming and isomerization processes), as well as the biodegradability and the washing characteristics (for n-alkanes dehydrogenation with the finalizing stage of alkylation);

4. Considering the catalyst deactivating processes of coke formation, poisoning, aging.

The mathematical models of multi-component catalytic processes designed thereby became the basis for simulating the software system implemented at the linear alkylbenzenes manufacturing plant. This allows solving important industrial problems connected with forecasting and optimization:

1. calculation of reactors optimal design;

2. calculation of optimal catalyst activity for maximum industrial unit capacity attaining; 


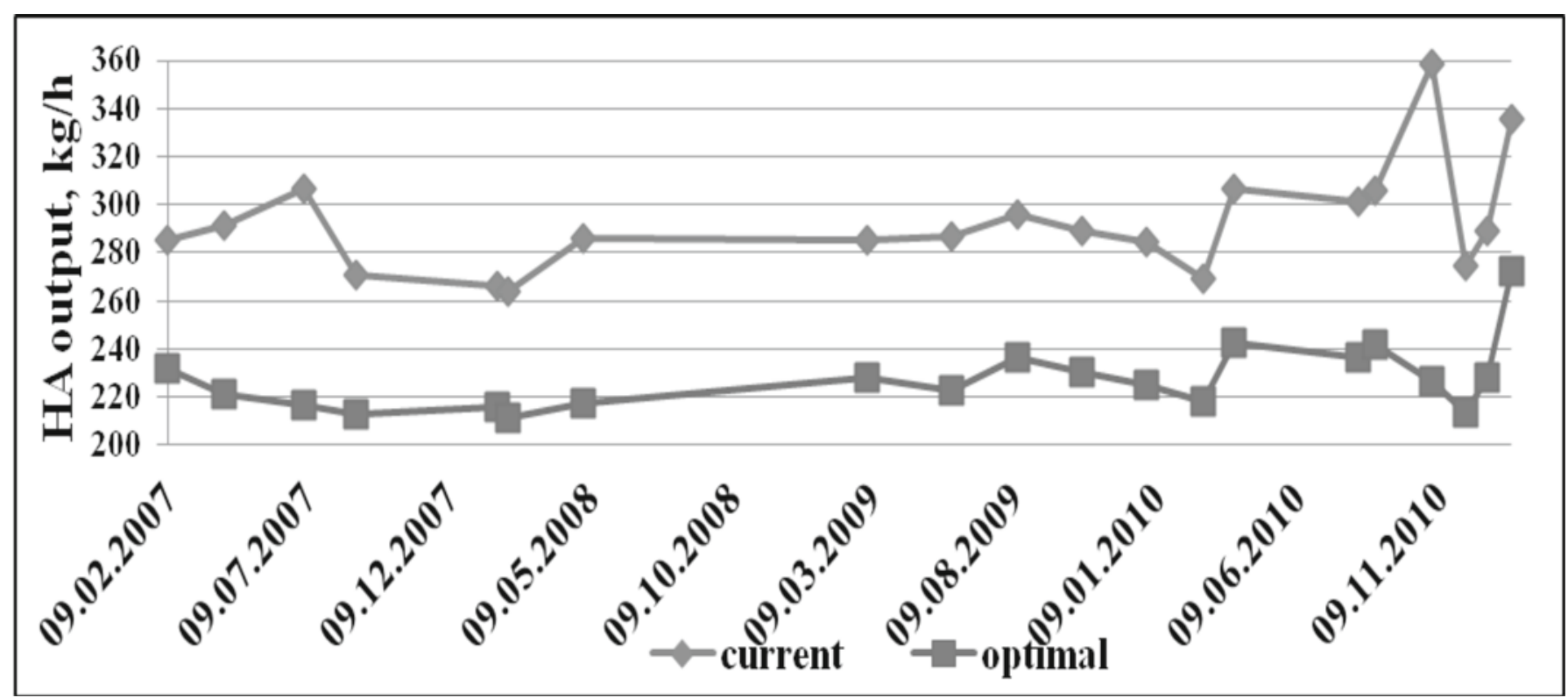

Figure 8. HA yield under the current and the optimal technological conditions

3. performance evaluation of any technological mode implementation without conducting a technological experiment;

4. optimization of deactivated catalyst surface regeneration;

5. construction, certification and implementation of intelligent computer systems for the improvement of industrial processes resource efficiency at the oil refinery.

\section{Nomenclature}

$X_{\text {uns }} \quad$ - mass fraction of the unsaturated compound in the product, $\%$

$M_{\text {uns }}$ - molar mass of the unsaturated compound, g/ mole

$\Delta G$ - change in Gibbs energy of reaction, $\mathrm{kJ} / \mathrm{mole}$

$\Delta H \quad$ - change in enthalpy of reaction, $\mathrm{kJ} / \mathrm{mole}$

$t \quad$ - time, sec

$C_{i} \quad$ - concentration of $i$-th component, mole $/ \mathrm{m}^{3}$

$\tau \quad-$ contact time, sec

$W_{\mathrm{i}}$ - rate of $i$-th component concentration change due to chemical reactions, mole $/\left(\mathrm{m}^{3} \cdot \mathrm{sec}\right)$

$\left(-\Delta H_{j}\right)-$ heat of $j$-th chemical reaction, $\mathrm{J} / \mathrm{mole}$

$C_{p} \quad-$ heat capacity of reacting mixture, $\mathrm{J} /($ mole $\cdot \mathrm{K})$

$T \quad$ - temperature, $\mathrm{K}$

$U \quad$ - linear flow rate, $\mathrm{m} / \mathrm{sec}$

$l \quad-$ linear dimension of reactor, $\mathrm{m}$

D - longitudinal diffusion coefficient, $\mathrm{m}^{2} / \mathrm{sec}$

$k \quad-$ reaction rate constant

$E_{\text {a }} \quad$ - activation energy, $\mathrm{kJ} /$ mole

$R \quad-$ universal gaseous constant, $\mathrm{J} /($ mole $\cdot \mathrm{K})$

$k \quad-$ Boltzmann constant, $\mathrm{J} / \mathrm{K}$

h $\quad-$ Plank constant, J·sec

$\Delta S^{\#} \quad$ - entropy change during transition complex formation, $\mathrm{J} /($ mole $\cdot \mathrm{K})$

$\Delta H^{\#}$ - enthalpy change during transition complex formation, $\mathrm{J} / \mathrm{mole}$

$\Delta G^{\#}$ - Gibbs energy change during transition complex formation, $\mathrm{J} / \mathrm{mole}$

$\varrho \quad-$ density of reacting mixture, $\mathrm{kg} / \mathrm{m}^{3}$

$\chi \quad-$ transmission coefficient

\section{LITERATURE CITED}

1. Noskov, A.S. (2005). Two centuries of mathematical modeling. Report at the problem seminar on 90-th anniversary of Slinko M.G.

2. Kravtsov, A.V., Ivanchina, E.D. (1996). Intelligent systems in chemical engineering and engineering education. Novosibirsk, Nauka.

3. Crane, J. (1961). Proceedings of the 4-th Int. Petroleum Congress, (3), 34.

4. Hutter, T. (1982). Development of kinetic model for catalytic reforming reactions: $P h D$ Dis.

5. Andrevskiy, V. (1982). Modeling and optimal control of catalytic reforming reactor units: $P h D$. Dis.

6. Buzko, V.Y., Suhno, I.V., Panyushkin, V.T. \& Ramazanova, D.N. (2005). Theoretical study of 1,4-dioxane complexes in the chair conformation with water by MNDO/PM3 semi-empirical method/ Journal of Structural Chemistry, (46), 618-624. DOI: 10.1007/s10947-006-0176-0.

7. Ivashkina, E.N. (2007). Improving of higher hydrocarbons $\mathrm{C}_{9}-\mathrm{C}_{14}$ dehydrogenation process efficiency: Ph.D. Dis.

8. Chenier P. (2002). Survey of Industrial Chemistry. Kluwer Academic/ Plenum Publishers.

9. Main constructive types of organic synthesis equipment. Retrieved October 15, 2011, from http://rudocs.exdat.com/docs/ index-29959.html.

10. Anslyn, E.V., Dougherty, D.A. (2006). Modern physical organic chemistry, California: University Science Books.

11. Reutov, O. A., Kurtz, A.L., Butin, K.P. (2009). Organic chemistry. Part 2. Moscow, MSU. 